\title{
Evidence based case report
}

\section{Relato de caso baseado em evidência}

\author{
Carlos Alberto Guimarães, TCBC-RJ'1
}

C linical cases are presented everywhere: on daily ward rounds, in seminars, in meetings, in the medical press and at conventions. Clinical case reports in the medical press represent a scientific effort comparable to other observational or experimental research projects. If the report is good, its publication should be encouraged without hesitation'.

Case reports can initiate scientific studies - they may serve to create a hypothesis that is put to the test using systematic research. But can case reports ever be evidence??2.

Do clinical case reports play a role in the present and future of evidence-based medicine (EBM)? Surely clinical case reports play a role in the present and future of EBM. In terms of EBM, a clinical case report can be viewed from two different angles: 1 ) it is a source of evidence, and 2) an evidence-based approach is needed in the interpretation of the case and in its clinical management. The first angle leads to the development of an "evidencebased case report". With respect to the second angle, it has been shown how available evidence can and should be used in an individual case of any disease ${ }^{1}$.

While clinicians are urged to use up-to-date research evidence to give patients the best possible care, actually doing so in individual patients is difficult. The research literature is poorly organized, largely of poor quality and irrelevant to clinical practice. The most valid and relevant information may be based on highly selected groups of patients with little resemblance to the patient in front of you ${ }^{3}$.

To help readers develop the increasingly necessary art of using research evidence in practice, the British Medical Journal launched a new type of article in 1998 - the evidence based case report ${ }^{4}$.

Evidence based case reports attempt to show how evidence can be applied at all stages of patient care.
Information from cohort studies about the frequency of different conditions can suggest the most likely diagnosis. Decisions about which tests to order can be guided by information on the sensitivity and specificity of different tests. Decisions about which interventions to advise can be gathered from randomized clinical trials and systematic reviews looking at effectiveness and safety. Information on long term or rare side effects can be acquired from well designed cohort or case control studies ${ }^{3}$.

Case reports have long been used to report new findings and to give educational impact to review articles. Evidence based case reports will not report new findings. Instead of presenting new findings, evidence based case reports are intended to illustrate a process. Contributors are being asked to take an approach now familiar to students of critical appraisal — to define the clinical question; to search the literature for studies of appropriate relevance, design, and quality; to apply the information; and to audit the result ${ }^{3}$.

In this issue, Guimarães et al. report, to our knowledge, the first evidence based case report published in a Brazilian journal, which is entitled "Evidence-based case report: agenesis or pseudo-agenesis of the dorsal pancreas".

\section{REFERENCES}

1. Jenicek M. Clinical Case Reporting in Evidence-Based Medicine. 2nd ed. London: Arnold; 2001.

2. Achenbach S, Einstein AJ, Ferencik M. How much evidence is in a case report? A road trip of scientific evidence, including skeptics, Ockham's razor, Hume's Fork, and Karl R. Popper [editorial]. J Cardiovasc Comput Tomogr. 2015;9(4):267-9.

3. Godlee F. Applying research evidence to individual patients. Evidence based case reports will help [editorial]. BMJ. 1998;316(7145):1621-2.

4. Glasziou P. Twenty year cough in a non-smoker. BMJ. 1998;30:316(7145):1660-1.

1. Comitê de Ética em Pesquisa do Hospital Universitário Clementino Fraga Filho da Universidade Federal do Rio de Janeiro. 